\title{
Assessment of association between hypothyroidism and hypertension among females of Hyderabad, Sindh, Pakistan
}

\author{
Naheed Shah ${ }^{1}$, Tahira Jabeen Ursani ${ }^{1}$, Nadir Ali Shah ${ }^{1}$ and Hafiz \\ Muhammad Zeeshan Raza ${ }^{2 *}$ \\ 1. Department of Zoology, University of Sindh, Jamshoro, 76080, Sindh-Pakistan \\ 2. Genomics and Computational Biology Laboratory, Biosciences Department, COMSATS University \\ Islamabad, Sahiwal Campus, Punjab-Pakistan \\ *Corresponding author's email: hafizraza26@gmail.com \\ Citation \\ Naheed Shah, Tahira Jabeen Ursani, Nadir Ali Shah and Hafiz Muhammad Zeeshan Raza. Assessment of \\ association between hypothyroidism and hypertension among females of Hyderabad, Sindh, Pakistan. Pure and \\ Applied Biology. Vol. 10, Issue 3, pp744-750. http://dx.doi.org/10.19045/bspab.2021.100076

\begin{tabular}{llll}
\hline \hline Received: 01/08/2020 & Revised: 18/11/2020 & Accepted: 24/11/2020 & Online First: 05/12/2020 \\
\hline
\end{tabular}

\section{Abstract}

Secondary hypertension has been associated with hypothyroidism. High blood pressure values and the prevalence of hypertension have been demonstrated in hypothyroid patients. Low cardiac output, increased peripheral and vascular resistance, arterial stiffness, high levels of norepinephrine in serum have been considered the mechanisms involved in developing diastolic hypertension in a state of hypothyroidism. To evaluate the association between hypertension and hypothyroidism, analysis of thyroid hormones levels and blood pressure values were determined in 450 chronic thyroiditis female patients of Hyderabad, Sindh, Pakistan. On the basis of TFT, T4 (thyroxine) and TSH (thyroid stimulating hormone) level in blood 298 females were categorized as euthyroid while 152 were hypothyroid [T4 (thyroxine) $=3.01 \pm 0.2 \mu \mathrm{g} / \mathrm{dl}$ and thyroid stimulating hormone $(\mathrm{TSH})=108.5+5.4 / \mu \mathrm{U} / \mathrm{ml}]$. In hypothyroid females with age more than 50 years, not systolic but diastolic blood pressure was recorded to be higher as compared to females of same age with euthyroid. In hypothyroid females, high prevalence of hypertension was observed with systolic/diastolic BP more than the reference value of $160 / 95 \mathrm{~mm} \mathrm{Hg}(15.4 \%$ vs. $6.3 \%$ and $\mathrm{p}$ value $<0.01)$. The data of both groups hypothyroid and euthyroid was collectively analyzed, significant correlations was found between thyroid hormones level T3 and $\mathrm{T} 4(\mathrm{r}=-0.159, p$ value $<0.01$, and $\mathrm{r}=-0.198$, $\mathrm{p}$ value $<0.01$ ). Replacement therapy of thyroid hormone can be used to normalize the thyroid function. It can be concluded that there was found a strong association of hypothyroidism and hypertension.

Keywords: Blood pressure, chronic thyroiditis, Hypothyroidism, Thyroid hormones, T3, T4, TSH

\section{Introduction}

Hypothyroidism is recognized as the causative agent for secondary hypertension $[1,2]$. In various books on hypertension, it is also listed as the cause of hypertension.
However there is not found any certainty about the prevalence of hypertensive disorders. The prevalence of hypertension because of hypothyroidism is $26 \%$ in Kaplan's Clinical Hypertension and 50\% in 
Genest's Hypertension, Physiology and Treatment [3]. Conversely, normal or low blood pressure had been reported in Skelton and Sonnenblick [4] in hypothyroid disorder.

Failure of the primary thyroid gland is mainly the common cause of hypothyroidism. Other causes that lead towards the development of primary hypothyroidism include postablative, autoimmune, athyreotic, goitrous, subacute thyroiditis, and Riedel's causes or (nonautoimmune) [5]. Hashimoto's disease, which is commonly called autoimmune lymphocytic thyroiditis, is the major reason for the dysfunctioning of thyroid gland. Replenishment of deficient hormones or iodine in the body can help in managing hypertension by lowering (BP) blood pressure resulting in the reduction of risks to the cardiovascular system [6]. In subclinical hypothyroidism, identical effects have also been observed [5].

Elevated values of blood pressure (systolic or diastolic) have been observed in various previous researches conducted to assess the prevalence of hypertension in hypothyroidism patients, however, one of the studies has also revealed not to have any relationship between hypothyroidism and hypertension [2, 7-14]. Saito et al. in his research conducted on females, concluded that in females with ages more than 50 years with mild hypothyroidism, the levels of thyroid hormones T3 (tri-iodothyronine) and T4 (thyroxine) have been significantly correlated with diastolic blood pressure [2]. The basic aim of this research is to demonstrate the association of hypothyroidism and hypertension to describe the thyroid function relation with blood pressure. It also involves a comparison of the increase in BP in relation to the age of females in hypothyroid and euthyroid patients. Generally hypertension is observed to be developed after 50 years of age in hypothyroid patient so the prevalence of hypertension in hypothyroid female will also be assessed.

\section{Material and Methods}

It was a prospective study comprised of 450 females diagnosed with chronic thyroiditis (hypothyroidism and euthyroid) to check the prevalence of associated hypertension in those who visited various private and government hospitals of Hyderabad, Sindh, Pakistan for assessment of their thyroid disorder during the period of 1 year, starting from March 2015 to February 2016. The study setting was different Hospitals of Hyderabad, including Civil Hospital Hyderabad, Aga Khan Hospital, NIMRA Hospital Hyderabad, Shah Bhitai Hospital Hyderabad, and Sindh Government Hospital Qasimabad, Hyderabad, after seeking approval by the governing bodies and ethics committee of the hospitals.

\section{Data collection}

The data was collected by using especially designed questionnaire, $\mathrm{x}$-rays reports, thyroid ultrasound reports and other laboratory test reports in order to analyze the hypothyroid and euthyroid females. The questionnaire was designed to collect information like general demographic data of the participants, which include weight, age, height, symptoms, systole and diastole blood pressure, etc. Body mass index was calculated using WHO criteria by calculating the weight of females in kilograms divided by taking the height square in meters $\left(\mathrm{Kg} / \mathrm{m}^{2}\right)$. The BMI of less than $18 \mathrm{Kg} / \mathrm{m}^{2}$ is considered underweight; $18.5-24.9 \mathrm{Kg} / \mathrm{m}^{2}$ as moderate; $25.0-29.9$ $\mathrm{Kg} / \mathrm{m}^{2}$ as overweight, and greater than 30 $\mathrm{Kg} / \mathrm{m}^{2}$ falls in the category of obese.

To evaluate the degree of deficiency regarding thyroid hormones, serum level of (tri-iodothyronine), T4 (thyroxine), and TSH was analyzed using radioimmunoassay techniques (ELISA), Immunoassay test kits to label the females in the category of euthyroid and hypothyroid. The obtained values of T3, T4 and TSH were expressed as means \pm SEM. The systolic and diastolic blood pressure was measured using a sphygmomanometer by considering systolic/diastolic arterial 
$\mathrm{BP}$ higher than $160 / 95 \mathrm{~mm} \mathrm{Hg}$ to be hypertensive.

\section{Statistical Analysis}

Statistical analysis of the data was done using software IBM SPSS version 20.0 by applying Student's $t$ test and chi square test for analysis of paired and unpaired data. By least squares method, correlations between variables (hypertension and hypothyroidism) were also calculated.

\section{Results and Discussion}

Comparison of Hypothyroidism and Euthyroidism in females

(Table 1) shows the BMI, height, and weight of females and (Table 2) shows the clinical serum levels of different thyroid hormones. Higher serum levels of T3 and T4, while low values of TSH were observed in euthyroid females However, BMI, weight, and height of females showed not much difference. The hypertension and its association on the basis of age in females with hypothyroidism and euthyroid is shown in (Table 3), which shows the prevalence of hypertension by age. In hypothyroid females, 21 out of 152 $(13.81 \%)$ and in euthyroid females, 15 out of $298(5.03 \%)$ had hypertension. For both hypothyroid and euthyroid females, blood pressure increased with age (Fig. 1). However, high diastolic blood pressure was found in hypothyroid females as compared to euthyroid females.

In euthyroid females, a high heart rate was present in comparison to hypothyroidism, but no statistical significance level was achieved in females with 40 years to 49 years and 60 years to 69 years (Fig. 2). Diastolic BP instead of systolic pressure in hypothyroid females was observed to be significantly correlated with $\mathrm{T} 3$ and $\mathrm{T} 4$ level with $\mathrm{r}$ value $=-0.215$ and value of significance $<0.01$, and $r=-0.209$ with the level of significance $p=<0.01$ and there was no correlation between TSH level and diastolic BP. In euthyroid females, none of the analyzed parameters showed any significant correlations all the thyroid hormones (TSH, T4, and T3) with blood pressure. When all the data of hypothyroid and euthyroid patients was collectively analyzed correlations was found between hormonal levels and diastolic blood pressure $\mathrm{T} 4(\mathrm{r}=-0.159, p$ value $<0.01$, and $r=-0.198, p$ value $<0.01)$.

Hypothyroidism has been accompanied by hypertension in many cases and the prevalence of hypertension among hypothyroid patients' needs to be evaluated as it varies from $0 \%$ to $50 \%$, which have been reported in many studies $[3,4,15]$. Moreover, few researches were conducted previously to compare changes in high blood pressure with the increase in age of patients with hypothyroid and euthyroid patients. In this research, only female population was selected to avoid gender based factors that may affect blood pressure. Obesity and adiposity is also an important factor which can enhance blood pressure [16, 17]. There was found no significant differences in body mass index, height, and weight among females with hypothyroid and euthyroid (Table 1). The recorded readings of systole and diastole blood pressure in euthyroid and hypothyroid women is also shown in (Table 4)

In the correlation studies there was found significant relation between diastolic blood pressure with T3 and T4 levels of hypothyroid females with $\mathrm{r}$ value $=-0.202$, and $p$-value of $<0.01$, and $r$ value $=-0.229$, with p-value $<0.01$. No significant correlation was found in hypothyroid group of females between TSH and diastolic blood pressure. Bergus conducted research on normal and hypothyroid patients to find association of hypertension with hypothyroidism. He also concluded there was no noticeable difference of blood pressure (diastolic ) of control and test groups [7]. These results also support our findings.

In euthyroid females, there was not observed any significant correlations between either of any thyroid hormone $\mathrm{TSH}, \mathrm{T} 4$ or T3, and blood pressure. The combined data of hypothyroid and euthyroid females presented significant 
correlations values of diastolic blood pressure with T3, or T4 respectively with $r$ value of $=-0.174$ and $p$-value to be $<0.01$, and $r$ value $=-0.208$ with $<0.01 \mathrm{p}$-value. Studies by [2, 7-14] on hypertension prevalence in hypothyroid subjects have also demonstrated the increase in systolic and diastolic Blood pressure values. The research by Saito et al. also showed the rise in diastolic BP with a significant correlation with T3 and T4 hormone in females aged more than 5o years and with hypothyroidism [2].

The hypertension and its association on the basis of age in females with hypothyroidism and euthyroid are shown in (Table 3), which shows the prevalence of hypertension by age. In hypothyroid females 21 out of $152(13.81 \%)$ and in euthyroid females 15 out of $298(5.03 \%)$ had hypertension. The blood pressure was observed to increase in both hypothyroid and euthyroid patients with the increase in age (Fig. 1). However, significantly high diastolic BP was observed in hypothyroid females as compared to females with euthyroid. In euthyroid females, heart rate was higher as compared to the hypothyroid females; nevertheless, the statistically significant level was not reached in the age range of 40 years to 49 years and 60 years to 69 year (Fig. 2)

In Japan, epidemiological study was conducted which revealed that in hypothyroid females with age more than 50 years, diastolic BP was significantly higher than euthyroid females in which BP changes were related to age was normal [18].The finding was in accordance with our results. It is suggested that hypothyroidism accelerates blood pressure with the passage of age. Systolic or diastolic blood pressure more 160/ $95 \mathrm{~mm}$ $\mathrm{Hg}$ on three consecutive measurements is referred as hypertension and its prevalence was observed to be significantly high in hypothyroid females in comparison to euthyroid female patients.

Iqbal et al also concluded his research that hypothyroidism is associated with a rise in both systole and diastole blood pressure [11]. Saltiki [12] also showed that systolic and diastolic hypertension was observed in hypothyroid patients. Non dipping status of hypertension in lower T3 levels was reported by Kanbay [13]. Liu et al. reported that females are more at the risk of developing hypertension in a state of subclinical hypothyroidism and strong association of hypertensive disorders are present in females with thyroid disorders [14]. A high prevalence of hypertension was reported by Endo and coworkers in mild hypothyroidism as compared to severe hypothyroidism [1]. The severity of deficiency of thyroid hormones in this study was considered to be slight to moderate, with average values of T4 levels to be $3.01 \pm 0.2 / \mu \mathrm{g} / \mathrm{dl}$ and $\mathrm{T} 3$ to be $66.9 \pm$ $4.1 \mathrm{ng} / \mathrm{dl}$ respectively, without any severe hypothyroidism symptoms.

In hypothyroidism the mechanism which is involved in causing increase in blood pressure has been associated with increase in stiffness of arteries [19, 20]. The accelerated changes in structure of vascular tissue due to deficiency of thyroid hormone may also be the factor of elevating total peripheral resistance resulting in High blood pressure. The early vascular aging index is increased PWV and is observed in subclinical hypothyroidism [19, 20]. In hypothyroidism norepinephrine level in blood also increases due to decrease in metabolism and high secretions due to thyroid dysfunction. High levels of prolactin and TSH are present in the serum of hypothyroid patient which suggest low activity of dopaminergic receptors in CNS, which may be involved in hypertension by increasing the release of nor-epinephrine [21]. Thyroid hormone replacement therapy has been proved to be successful in causing reduction of $\mathrm{BP}$, in hypothyroidism supporting the secondary hypertension causes [22]. After hormone therapy, there was also seen to be an increased in central aortic pressures and reversal of arterial stiffness [23]. 
Table 1. Weight, height and BMI of Female patients

\begin{tabular}{|c|c|c|c|}
\hline \multirow{2}{*}{ Parameters } & $\begin{array}{c}\text { Hypothyroid } \\
\mathbf{N = 1 5 2}\end{array}$ & $\begin{array}{c}\text { Euthyroid } \\
\mathbf{N = 2 9 8}\end{array}$ & $\begin{array}{c}\text { Level of } \\
\text { significance }\end{array}$ \\
\cline { 2 - 4 } & Mean \pm SEM & Mean \pm SEM & $\boldsymbol{p}$-value \\
\hline Height $(\mathbf{c m})$ & $150.5 \pm 0.9$ & $159.0 \pm 1.3$ & 0.451 \\
\hline Weight $(\mathbf{K g})$ & $50.2 \pm 2.4$ & $53.1 \pm 2.0$ & 0.263 \\
\hline BMI $\left(\mathbf{K g} / \mathbf{m}^{\mathbf{2}}\right)$ & $23.6 \pm 0.7$ & $24.1 \pm 0.3$ & 0.179 \\
\hline
\end{tabular}

Table 2. Thyroid Hormones level in serum of female patients

\begin{tabular}{|c|c|c|c|}
\hline \multirow{2}{*}{ Thyroid Hormones } & $\begin{array}{c}\text { Hypothyroid } \\
\mathbf{N = 1 5 2}\end{array}$ & $\begin{array}{c}\text { Euthyroid } \\
\mathbf{N = 2 9 8}\end{array}$ & $\begin{array}{c}\text { Level of } \\
\text { significance }\end{array}$ \\
\cline { 2 - 4 } & Mean \pm SEM & Mean \pm SEM & $\boldsymbol{p}$-value \\
\hline TSH $(\boldsymbol{\mu U} / \mathbf{m l})$ & $108.5+5.4$ & $3.2 \pm 0.1$ & $<0.001$ \\
\hline T3 $(\mathbf{n g} / \mathbf{d l})$ & $66.9 \pm 4.1$ & $115.7 \pm 2.5$ & $<0.001$ \\
\hline T4 $(\boldsymbol{\mu g} / \mathbf{d l})$ & $3.01 \pm 0.2$ & $7.8 \pm 0.4$ & $<0.001$ \\
\hline
\end{tabular}

Table 3. Prevalence of hypertension in females based on their age

\begin{tabular}{|c|c|c|c|}
\hline \multirow{2}{*}{ Age (Years) } & \multicolumn{2}{|c|}{ Females with hypertension } & $\begin{array}{c}\text { Level of } \\
\text { significance } \\
\text { p-value }\end{array}$ \\
\cline { 2 - 4 } & Hypothyroid & Euthyroid & $\mathbf{0 . 1 4 2}$ \\
\hline $\mathbf{2 0 - 2 9}$ & $0 / 17(0 \%)$ & $0 / 49(0 \%)$ & $\mathbf{0 . 1 2 1}$ \\
\hline $\mathbf{3 0 - 3 9}$ & $3 / 24(12.5 \%)$ & $4 / 69(5.79 \%)$ & $\mathbf{0 . 1 4 7}$ \\
\hline $\mathbf{4 0 - 4 9}$ & $5 / 36(13.88 \%)$ & $6 / 98(6.12 \%)$ & $\mathbf{0 . 0 0 1}$ \\
\hline $\mathbf{5 0 - 5 9}$ & $9 / 52(17.3 \%)$ & $4 / 57(7.01 \%)$ & $\mathbf{0 . 2 1 8}$ \\
\hline $\mathbf{6 0 - 6 9}$ & $4 / 23(17.39 \%)$ & $1 / 25(4 \%)$ & $\mathbf{0 . 0 1 1}$ \\
\hline Total & $21 / 152(13.81 \%)$ & $15 / 298(5.03 \%)$ & \\
\hline
\end{tabular}

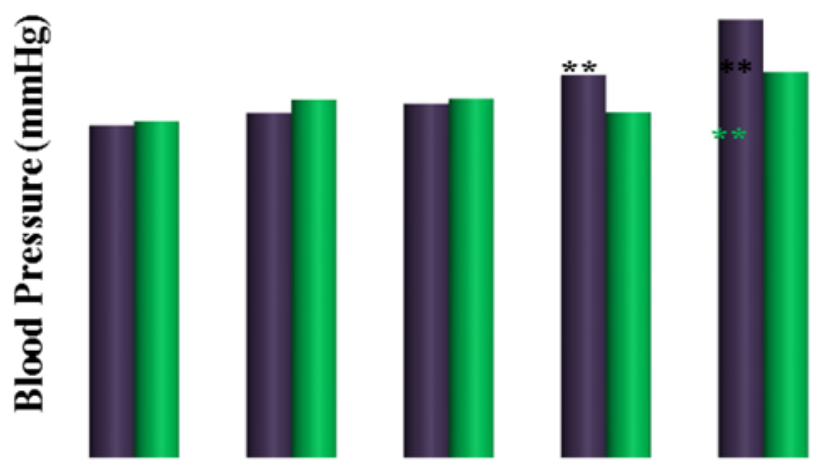

Hypothyroid

Euthyroid

Age (Years)

**p $<001$ (unpaired $t$ test)

Figure 1. Based on age, blood pressure in hypothyroid and euthyroid females 


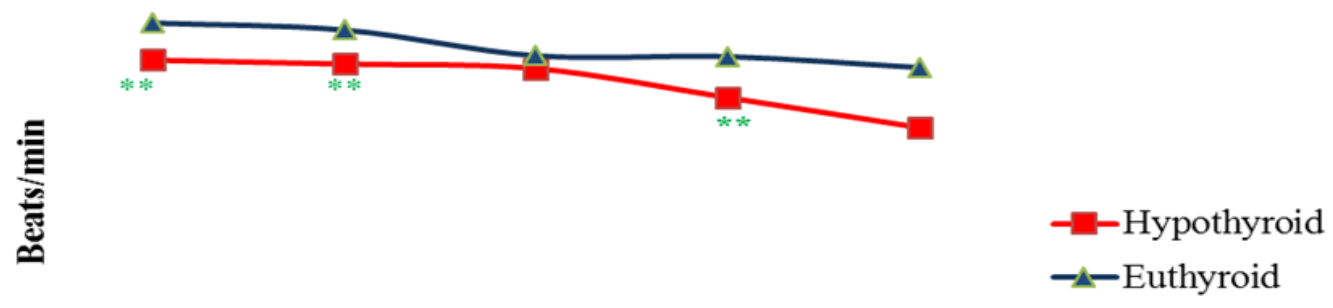

Age (Years)

**p $<0.05$ (Unpaired $\mathrm{t}$ test)

Figure 2. Based on age, cardiac rate (Means \pm SEM) in hypothyroid and euthyroid

Table 4. Blood pressure female patients

\begin{tabular}{|c|c|c|c|}
\hline \multirow{2}{*}{$\begin{array}{c}\text { Blood pressure } \\
(\mathbf{m m H g})\end{array}$} & $\begin{array}{c}\text { Hypothyroid } \\
\mathbf{N = 1 5 2}\end{array}$ & $\begin{array}{c}\text { Euthyroid } \\
\mathbf{N}=\mathbf{2 9 8}\end{array}$ \\
\cline { 2 - 3 } & Mean \pm SEM & Mean \pm SEM \\
\hline & Diastolic & $99.8 .0 \pm 4.8$ & $98.9 \pm 7.6$ \\
\hline & Systolic & $159.5 \pm 19.2$ & $151.9 \pm 4.9$ \\
\hline
\end{tabular}

\section{Conclusion}

It was confirmed after this research that hypertension is associated with thyroid disorder known as hypothyroidism in females with ages more than 50 years as compared to the euthyroid patients, and blood pressure can be managed by giving sufficient thyroid hormone replacement therapy. The mechanisms involved in hypertension are arterial stiffness, an increase in peripheral resistance and norepinephrine levels so the low activity of dopamine due to deficiency of thyroid hormone lead towards the increase in a sympathetic nervous tone, which is responsible for the development of hypertensive disorders. It can be concluded that hypothyroidism is the cause of hypertension, more prevalent in females, and its risks increase with the increase in age.

\section{Authors' contributions}

Conceived and designed the experiments: NA Shah, Performed the experiments: N Shah \& NA Shah, Analyzed the data: TJ Ursani, Contributed materials/ analysis/ tools: N Shah \& TJ Ursani, Wrote the paper: N Shah \& HMZ Raza.

\section{References}

1. Wong KK, Shulkin BL, Gross MD \& Avram AM (2018). Efficacy of radioactive iodine treatment of graves' hyperthyroidism using a single calculated 131 I dose. Clin. Diabetes Endocrinol 4(1): 1-8.

2. Chandna S \& Bathla M (2011). Oral manifestations of thyroid disorders and its management. Indian J Endocrinol Metab 15(Suppl2): S113.

3. Narayana S K, Woods DR \& Boos CJ (2011). Management of amiodaronerelated thyroid problems. Ther $A d v$ Endocrinol Metab 2(3): 115-126.

4. Vanderpump MPJ (2011). The epidemiology of thyroid disease. $\mathrm{Br}$ Med Bull 99(1).

5. Talat A, Khan AA, Nasreen $S$ \& Wass JA (2019). Thyroid Screening During Early Pregnancy and the Need for Trimester Specific Reference Ranges: A Cross-Sectional Study in Lahore, Pakistan. Cureus 11(9). 
6. Sajid N, Riaz M, Fawwad A \& Basit A (2019). Thyroid dysfunction in subjects with type 1 diabetes at a tertiary care unit of Karachi, Pakistan. Clin Epidemiol Glob Heal 7(3): 435438.

7. Ahmad T, Khoja A, Rashid NH \& Ashfaq MA (2018). Outcome of radioactive iodine therapy in Toxic Nodular Goiter in Pakistan. Pak J Pharm Sci 34(5): 1146.

8. Naz N, Rizvi S \& Sadiq Z (2017). Assessment of thyroid hormone levels and thyroid disorders: A case study from Gujranwala, Pakistan. Pak $J$ Pharm Sci 30(4).

9. Rehman R, Zafar A, Fatima SS, Mohib A \& Sheikh A (2020). Altered Sperm Parameters and Subclinical hypothyroidism; a cross sectional study in Karachi, Pakistan. Int J Clin Pract e13555.

10. Attaullah S, Haq BS \& Muska M (2016). Thyroid dysfunction in Khyber Pakhtunkhwa, Pakistan. Pak J Med Sci 32(1): 111.

11. Bose A, Sharma N, Hemvani N \& Chitnis DS (2015). A hospital based prevalence study on thyroid disorders in Malwa region of Central India. Int J Curr Microbiol Appl Sci 4(6): 604611.

12. Gessl A, Lemmens GR \& Kautzky WA (2013). Thyroid disorders. In Sex and Gender Differences in Pharmacology. Springer pp. 361-386.

13. Ahmed RG (2017). Hyperthyroidism and developmental dysfunction. Arch Med 9(4): 6.

14. Dittrich R, Beckmann MW, Oppelt PG, Hoffmann I, Lotz L, Kuwert T \& Mueller A (2011). Thyroid hormone receptors and reproduction. J Reprod Immunol 90(1): 58-66.

15. Mansourian AR (2013). Female reproduction physiology adversely manipulated by thyroid disorders: A review of literature. Pak J Biol Sci 16(3): 112-120.

16. Medici M, Ghassabian A, Visser W, Muinck KS, Jaddoe VW, Visser W E \& Bongers SJ (2014). Women with high early pregnancy urinary iodine levels have an increased risk of hyperthyroid newborns: the population-based $\mathrm{G}$ eneration RS tudy. Clin Endocrinol 80(4): 598-606.

17. Seigel SC \& Hodak SP (2012). Thyrotoxicosis. Med Clin. 96(2): 175201.

18. Lee SY, Rhee CM, Leung AM, Braverman LE, Brent GA \& Pearce EN (2015). A review: radiographic iodinated contrast media-induced thyroid dysfunction. J Clin Endo Met 100(2): 376-383.

19. Taylor PN, Albrecht D, Scholz A, Gutierrez G, Lazarus JH, Dayan CM \& Okosieme OE (2018). Global epidemiology of hyperthyroidism and hypothyroidism. Nat Rev Endocrinol 14(5): 301

20. Abraham NM, Bystrom K, Torring O, Lantz M, Berg G, Calissendorff J \& Karlsson FA (2011). Incidence of hyperthyroidism in Sweden. Eur $J$ Endocrinol 165(6): 899.

21. Lee H, Hodi FS, Giobbie Hurder A, Ott PA, Buchbinder EI, Haq R \& Donahue H (2017). Characterization of thyroid disorders in patients receiving immune checkpoint inhibition therapy. Cancer Immunol Res 5(12): 1133-1140.

22. Deokar PG, Nagdeote AN, Lanje MJ \& Basutkar DG (2016). Prevalence of thyroid disorders in a tertiary care center. Int J Curr Res Rev 8(9): 26.

23. Kahaly GJ, Bartalena L, Hegedus L, Leenhardt L, Poppe K \& Pearce SH (2018). European thyroid association guideline for the management of Graves' hyperthyroidism. Eur Thyroid J 7(4): 167-186. 